Geografia e Ordenamento do Território, Revista Electrónica

Centro de Estudos de Geografia e Ordenamento do Território

http://cegot.org

ISSN :2182-1267

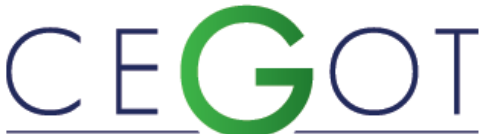

Centro de Estudos de Geografia e Ordenamento do Território
BOUÇAS, LAILA

Programa de Pós Graduação em Arquitetura e Urbanismo - PPG-AU/UFBA / Universidade Federal da Bahia, Faculdade de Arquitetura ua Caetano Moura, 121 - Federação, Salvador-BA. 40210-905, Brasil

lailaboucas@gmail.com

\title{
O trabalho na rua: uma relação entre espaço público, planejamento e direito à cidade
}

The work on the street: a relationship between public space, planning and the right to the city

Referência: Bouças, Laila (2017). O trabalho na rua: uma relação entre espaço público, planejamento e direito à cidade. Revista de Geografia e Ordenamento do Território (GOT), n.o 12 (dezembro). Centro de Estudos de Geografia e Ordenamento do Território, p. 49-73, dx.doi.org/10.17127/got/2017.12.003

\section{RESUMO}

Este artigo constitui-se como parte do que foi desenvolvido em uma pesquisa de mestrado, que estudou a maneira como a atividade dos trabalhadores de rua está inserida e se relaciona com o espaço público, bem como sobre como incidem as ações de planejamento e ordenamento sobre a mesma, numa área do centro da cidade de Salvador. Uma das teorias chave para o desenvolvimento da pesquisa é a dos circuitos da economia desenvolvida pelo professor Milton Santos, que servirá como lastro teórico fundamental para compreensão da dinâmica analisada. Busca-se ainda neste trabalho, levar o olhar para a tentativa de ordenamento do espaço público promovida por uma gestão municipal, compreendida no âmbito do planejamento estratégico, que confere uma visão empresarial sobre a cidade, favorecendo aspectos que visam torná-la competitiva frente às demais.

Palavras-chave: trabalhador de rua; espaço público; apropriação; planejamento estratégico.

\section{ABSTRACT}

This article results of a Master's research, which aimed at analyzing the way in which the activity of street workers is inserted and related to the public space, as well as how it's affected by urban planning in an area in the city center of Salvador. To do so, the theory of 
the circuits of the economy developed by Milton Santos is such a fundamental theoretical basis to understand the case study. So, this paper aims to take a look at the attempt to organize the public space by the city government, understood within the scope of strategic planning, which understands the city from a business perspective, favoring aspects in order to put it in a competitive position vis-à-vis other ones.

Keywords: street worker; public space; appropriation; strategic planning

\section{Introdução}

Nas cidades, sobretudo nas latino-americanas, confrontamos diariamente as ocupações informais da "cidade real", contrapostas as da "cidade ideal" (SAMPAIO, 1999), planejada, isto quando nosso olhar se volta para as formas de habitar. Porém, tais usos e apropriações comumente classificados como informais não se restringem à casa ou a tipologia de sua construção, estendem-se sob variados formatos que interferem na forma, paisagem e ordenamento da cidade "ideal". Diversas são as expressões cotidianas daqueles que se apropriam e interferem no que foi previamente planejado ou concebido para o espaço urbano, em que destacamos para este estudo a atividade desempenhada pelos trabalhadores de rua, que se expressa no espaço público.

A atividade desempenhada por tais trabalhadores no espaço da rua não é mero acaso. Trata-se de trabalhadores que não foram absorvidos pelo mercado de trabalho formal e que revelam uma das faces das desigualdades de oportunidades a que está submetida grande parte da população urbana brasileira. Diversos teóricos tentaram entender o fenômeno e sua polarização simbolizada na discussão sobre os setores formal e informal da economia. Oliveira (2003) e Santos (2008), dentre outros, nos mostraram que essa dualidade era mais complexa do que os termos "formal" ou "informal" podiam denunciar, pois em verdade tratava-se de duas faces de um mesmo processo em nossa economia. Agregando a noção de espaço em sua formulação teórica sobre o assunto, Santos (2008) em termos gerais demonstrou que num mesmo sistema coexistem e se retroalimentam dois circuitos da economia ${ }^{1}$ : um superior, no qual é possível satisfazer todas as necessidades de consumo, e o inferior, em que se tendo as mesmas necessidades não há o mesmo poder de consumo.

\footnotetext{
${ }^{1}$ A diferença entre os dois circuitos está fundamentalmente baseada nas diferenças de tecnologia e organização. No circuito superior é utilizada uma tecnologia de alto nível, ou seja, o capital é intensivo. Já no
} 
Aproximando-nos de nosso objeto de estudo, inseridos no circuito inferior da economia, temos os trabalhadores de rua e a apropriação da rua para o exercício de sua atividade laboral, o que provavelmente implica em disputa por esse espaço desde seu primeiro instante. Para que uma pessoa defina seu ponto num determinado lugar, é preciso minimamente que a mercadoria ofertada seja aceita pela população, que haja demanda. $\mathrm{Na}$ medida em que a demanda gerada agrada é possível que o ponto possa se estabelecer. Isso significa que uma apropriação inicial aos poucos se converte em uso e este uso, por sua vez, converte-se em conquista social na medida em que é reconhecido como um direito. Este reconhecimento ganha força principalmente quando o poder público passa a legislar sobre o assunto e cria normas específicas para ordenar a maneira como o uso do logradouro público pode se dar. Neste artigo pretende-se, portanto, explorar a relação entre as ações do poder público e a apropriação da rua pelo trabalho.

\section{Noções sobre a informalidade}

Para o desenvolvimento desta pesquisa ${ }^{2}$, considerou-se importante inicialmente compreender quem são os trabalhadores de rua $^{3}$ na cidade de Salvador e isso implicou saber em que categoria eles estavam enquadrados, como esse trabalho funcionava, como ele estava inserido nos modos de produção capitalista e, consequentemente, quais eram os desdobramentos da atividade no espaço. Que significado tem para a cidade o trabalho da pessoa que usa o espaço da rua para comercialização de mercadorias? A que categoria da

circuito inferior a tecnologia é justamente o trabalho intensivo e as atividades se baseiam no crédito e no dinheiro líquido. Além disso, os empregos raramente são permanentes e a remuneração, de maneira geral, situa-se abaixo do mínimo que uma pessoa precisa para ter uma vida digna, ou seja, para ter acesso à educação, saúde, moradia, alimentação, lazer etc.

${ }^{2}$ Este artigo é resultado de uma pesquisa de mestrado da autora, que culminou na dissertação intitulada "No olho da rua: trabalho e vida na apropriação do espaço público pelo trabalhador de rua em Salvador/BA".

${ }^{3}$ O termo "camelô" começou a ser definido em 1869, conforme Mollier (2009), por Pierre Larrousse no Dictionnaire Universel du XIXe siècle. Nele, o termo camelot referia-se ao "vendedor ambulante que empurra uma carreta com os braços e encurvando as costas, o que faz lembrar um camelo". O termo "ambulante" dá a ideia de alguém que muda de lugar o tempo todo, não possuindo um lugar fixo de trabalho. Prefere-se neste trabalho utilizar o termo "trabalhador de rua", por ser mais abrangente, além de poder ser utilizado tanto para aqueles que possuem pontos transitórios, como também para aqueles que possuem pontos fixos de trabalho. Vai desde aos que estão numa situação regular com a municipalidade e também aos que não estão, pois o que se quer evidenciar principalmente é que se trata de trabalhadores que usam o espaço da rua. 
economia este trabalho pertence? Para aproximar-nos das respostas às essas questões é preciso entender, mesmo que brevemente, o que é a informalidade e como ela se apresenta no Brasil.

De acordo com Costa (2010, p.175), "o trabalho informal pode ser conceituado como aquele não regulamentado pelo ordenamento legal do trabalho no país, sobre o qual, inclusive, a sociedade construiu sua política de seguridade social". Nesse sentido, as políticas de seguridade desenvolvidas pelo Estado dirigiam-se apenas para os trabalhadores formalmente reconhecidos, o que significa para a autora uma "cidadania regulada", ou seja, aquela adquirida unicamente pelos indivíduos enquadrados na estrutura ocupacional definida e reconhecida pelo Ministério do Trabalho. Nesse contexto, é importante ainda mencionar a Consolidação das Leis Trabalhistas (CLT) que veio para assegurar os direitos dos trabalhadores no campo individual, com o limite à jornada de trabalho de 8 horas, salário mínimo, férias, 13ำ salário, entre outros benefícios e que também assegura a representação coletiva, ou seja, a negociação dos termos de trabalho entre patrões e trabalhadores, através dos sindicatos. Entretanto, esses direitos se dirigem apenas aos trabalhadores formais.

A divisão da economia em formal e informal para Filgueiras et al. (2004), além de ser muito simplista, também associa o setor informal aos segmentos mais pobres da população, sem considerar as formas de inserção do trabalhador na produção. Os autores chamam atenção ainda para o fato de, no Brasil, a informalidade ter sido intensa desde o pós-guerra. De acordo com Costa (2010) a rápida urbanização dos anos 60 e 70 não foi capaz de absorver os indivíduos que migraram para as cidades; ela se expandiu, porém não foi capaz de gerar os empregos na mesma proporção dos que destruiu ou dos que a sociedade necessitava. Desse processo decorreu a criação de novas modalidades de trabalho informal ou o próprio desemprego.

Segundo Filgueiras et al (2004) no início dos anos 1980 houve um intenso processo de desestruturação do mercado de trabalho, onde já se prenunciava a precarização do emprego. Para Costa (2010) foi a partir da referida década que as mudanças analíticas do problema da informalidade passaram a se dar em torno de duas situações principais: em torno da perda da centralidade e do dinamismo do setor secundário (que não gerava mais 
tantos empregos); e em torno da crescente força do setor de serviços na absorção da força de trabalho. A informalidade generalizou-se nesse período, em que se disseminou o discurso de que o caminho para a modernidade passava por reformas no âmbito das privatizações e da desregulamentação dos mercados produtivos e de trabalho.

Ainda segundo Costa (2010) na década de 1990 há uma acentuação no retraimento da economia organizada e do trabalho formal. Com o advento da terceirização, empregos regulares que contavam com certo acúmulo de conquistas sociais foram substituídos por empregos precários, temporários e/ou não regulamentados. De acordo com Borges (2007) as transformações dos anos 1990 impactaram a vida dos brasileiros mudando o padrão de desenvolvimento, as formas e mecanismos de inserção e de permanência no mercado de trabalho, e os projetos para o futuro de diversos trabalhadores. Passou-se de uma economia fechada para uma economia aberta, desregulamentada, voltada a atender os interesses neoliberais de agentes externos, que ganharam maior influência, sobretudo, através das privatizações de setores estratégicos da economia nacional.

Finalmente, nesse período, passou-se de uma economia com elevado dinamismo no seu mercado de trabalho, com geração contínua de postos de trabalho (bons e ruins), para uma economia que destrói os melhores empregos e gera, quase que exclusivamente, postos de trabalho mal remunerados, desprotegidos e em número insuficiente. Com isto, o mercado de trabalho brasileiro, estruturalmente marcado pela presença expressiva da informalidade e do subemprego, aprofunda esses traços e a eles agrega elevadíssimas taxas de desemprego aberto e oculto. (BORGES, 2007:82)

Para Filgueiras et al (2004) a globalização e a reestruturação produtiva na década de 1990 também possuem um papel de destaque, pois resultaram em altas taxas de desemprego, acentuação da precarização do trabalho e do emprego, e crescimento das atividades não regulamentadas. A globalização, por sua vez, favoreceu as empresas a fixarem-se onde havia mais recursos para seus negócios (por exemplo: isenção de impostos e mão de obra barata). Nesse período, no Brasil, foram registradas as maiores taxas de desemprego da história, bem como uma expansão bastante expressiva do setor de serviços, que mesmo assim não foi capaz de absorver o contingente de trabalhadores existente. Ainda de acordo com os autores supramencionados, a ampliação da informalidade com a transferência dos trabalhadores que outrora realizavam atividades formais (legais) para as atividades informais (ilegais), deu origem a chamada nova informalidade. 
Em um momento recente de nossa história, mais precisamente nos anos 2000, uma melhora ${ }^{4}$ na situação do trabalho e do emprego é verificada no país, porém por um período muito breve (DIEESE, 2011). Essa frágil melhora não se sustenta face à crise financeira mundial de 2008, que só atingiu a economia brasileira anos depois, em 2015, levando a uma nova desestruturação do mercado de trabalho brasileiro, num mundo ainda mais globalizado, marcado pela acumulação flexível e pela precarização do trabalho, ou seja, por um trabalho que é muito mais instável e inseguro, pouco capaz de garantir alguma estabilidade no futuro. Sobre este aspecto ainda, de acordo com o DIEESE (2011), em 10 anos houve, de maneira simultânea, a redução do número de trabalhadores que associam a procura de trabalho com o exercício de bicos, e o crescimento para 35,6\% da proporção daqueles que declararam ter perdido ou deixado o último emprego nos últimos 4 meses. Cabe destacar ainda que 40,7\% dos desempregados em 2009 permaneceram por até 6 meses no último posto de trabalho, ou seja, um tempo bastante curto.

A evolução da discussão sobre a informalidade é extremamente importante para compreendermos as modificações que o emprego e o trabalho sofreram nas últimas décadas, sobretudo porque muitos destes que enfrentaram dificuldades para entrar no mercado de trabalho desde a década de 1990, são ainda hoje as pessoas que utilizam o espaço da rua para comercialização de mercadorias.

Nesse sentido, temos o que Santos (2008) apresenta sobre o circuito inferior, entendido como uma consequência das desigualdades oriundas do modelo de crescimento econômico vigente, baseado em uma distribuição de renda desigual. Entender como esses fatores se organizam é entender como a sociedade se organiza no espaço. Com relação aos trabalhadores de rua, Santos (2008) entende que os mesmos compõem o nível inferior da pulverização do comércio, configurando-se como o "último elo da cadeia de intermediários entre importadores, industriais, atacadistas e o consumidor" (SANTOS, 2008:218). Esta categoria destaca-se por ter menor dependência com relação à sua clientela, uma vez que

\footnotetext{
${ }^{4}$ Segundo o DIEESE (2011) o período entre 2004 e 2008 foi considerado o mais próspero da década, com melhoria nos indicadores sociais e na redução do desemprego, onde a ocupação cresceu em ritmo superior ao crescimento da População Economicamente Ativa (PEA). De acordo com o referido Departamento ainda, os fatores que tornaram essa realidade possível foram a confluência de resultados positivos da gestão interna e do ambiente internacional favorável. A partir de 2004 a nova dinâmica do mercado de trabalho brasileiro centrou-se no comportamento do Produto Interno Bruto (PIB) e na expansão dos investimentos.
} 
desloca-se à sua procura. Analisar a configuração do trabalho exercido na rua e o rebatimento dessa atividade no espaço que ocupa ajuda, portanto, a entender uma das formas como a economia se expressa no espaço aqui observado, a Avenida Sete de Setembro em Salvador.

\section{O trabalho no espaço público}

O espaço público reflete as tensões do processo de produção e reprodução do espaço urbano e os conflitos de interesse público-privados existentes. O espaço, de acordo com Santos (1985), pode ser compreendido como uma instância da sociedade, um fator da evolução social que contém e é contido pelas demais instâncias. A essência do espaço é, portanto, social, onde ele constitui-se não somente pela paisagem (configuração geográfica), mas pela soma da mesma com a sociedade. As diferentes maneiras como este espaço é apropriado, por sua vez, são resultado da maneira como a sociedade se organiza, o que perpassa pela distribuição de renda entre os indivíduos e por suas necessidades de produção e consumo.

O espaço, portanto, não é um lugar passivo, como nos lembra Lefebvre (2000), pois nele são contrapostas as forças das relações sociais, onde a hegemonia de uma classe se superpõe sobre a sociedade como um todo. Para este autor, o espaço é antes de tudo um produto social, produzido e com características próprias oriundas de cada sociedade. Ele contém lugares apropriados pelas relações sociais de reprodução e pelas relações de produção que Ihes engendram, organizadas de acordo com a divisão do trabalho.

O espaço público, por sua vez, reflete as tensões do processo de produção e reprodução do espaço urbano e os conflitos de interesse público-privados existentes. O espaço público é um conceito próprio do urbanismo, conforme Borja (2003), e costuma ser erroneamente confundido com espaços verdes, equipamentos urbanos ou com o próprio sistema viário, mas também aparece no campo da filosofia política como lugar de representação coletiva da sociedade. O autor relaciona a noção do espaço público com a cidade e com a noção de cidadania, entendida como um conceito do direito público. Ele trata da dialética existente entre esses três conceitos e afirma que quanto mais espaços públicos uma cidade possua, 
mais cidadania ela terá e, consequentemente, mais conflitos haverá sobre o uso deste espaço. Isto porque, para o autor, o espaço público é o local em que a representação da sociedade se torna visível. É um lugar de relação e de identificação entre as pessoas, de contato, de animação urbana e até mesmo de expressão comunitária.

O espaço público supõe, portanto, domínio público, uso social e coletivo e multifuncionalidade. Se caracteriza fisicamente por sua acessibilidade, o que o converte em um fator de centralidade. A qualidade do espaço público poderá ser avaliada, sobretudo, pela intensidade e qualidade das relações sociais que facilita, por sua capacidade para gerar misturas de grupos e comportamentos, por sua qualidade de estimular a identificação simbólica, a expressão e a integração cultural. Por isso, é necessário que o espaço público seja pensado como obra de qualificação do entorno, de intrínseca qualidade, assim como a continuidade no espaço urbano e sua capacidade de organização, a generosidade de suas formas, de seu desenho e materiais e a adaptabilidade a usos diversos através do tempo. (BORJA, 2003:122; tradução nossa)

Para Borja e Muxí (2000), o espaço público não pode ser considerado como um espaço residual, pois é o local que permite o passeio e o encontro, além de ordenar cada zona da cidade, dando-lhes sentido. É um lugar ao mesmo tempo físico, simbólico e político. Para este autor, a história de uma cidade se confunde com a história do seu espaço público, pois é nele que se materializam as relações entre os habitantes e o poder público. Deve, portanto, garantir a apropriação por parte de diferentes coletivos sociais e culturais, de idade e de gênero, em termos de igualdade.

Considera-se, nesse sentido, que o papel da rua merece ser destacado tendo em vista que ela se constitui enquanto espaço público em essência, onde se observa a atividade pesquisada. A rua também pode ser entendida como lugar da socialização, da circulação, do comércio e das trocas. Pode-se considerar que a apropriação deste espaço público pelos comerciantes dinamiza o seu uso, conferindo características a este lugar que não podem ser observadas com a mesma ênfase em outros locais da cidade. As ruas talvez sejam o local da cidade onde mais claramente se evidencia o dissenso e as contradições contidas no processo de planejamento.

Jacobs (2011) observa que para que uma rua se mantenha sua dinâmica, ou seja, para que tenha vida, é preciso que gere diversidade. Para isso, a monotonia residencial deve ser quebrada pela presença de opções de comércio variadas e de atrativos culturais. Teoricamente isso torna-se mais fácil de ser alcançado pelas cidades grandes, naturalmente 
geradoras de diversidade e incubadoras de novos empreendimentos e ideias. Contudo, isto só se verifica na prática se houver diversas e eficientes combinações de usos econômicos na cidade. As situações capazes de gerar tal diversidade dependem, para a autora, basicamente de quatro condições essenciais: 1) atender a mais de duas funções principais (lazer, moradia e trabalho, por exemplo), o que garante que haja pessoas saindo em diferentes horários e otimiza o uso da infraestrutura disponível; 2) as quadras devem ser curtas, o que possibilita aos usuários a oportunidade de virar esquinas, ou seja, diminui-se a possibilidade de existirem ruas isoladas, separadas e desassistidas pela população; 3) uma combinação de edifícios de idades e estados de conservação diversos, o que pode gerar rendimento econômico variado, pois prédios antigos podem ser alugados por comércios ou serviços que não tem recursos para investir em novos edifícios; 4) densidade alta de pessoas, sobretudo incluindo pessoas com o propósito de morar no lugar. Este último aspecto é importante por favorecer a concentração de pessoas no bairro, que habitualmente são as que mais consomem dos pequenos comércios, o que amplia mais a diversidade de usos.

Tais condições problematizadas por Jacobs (2011), mais do que garantir o uso das ruas, implicam também em sua apropriação pelos mais diversos tipos de usuários. Na rua, a apropriação de suas formas, por sua vez, pode ocorrer de diversas maneiras. Para Santos \& Vogel (1985) apropriar-se de um ponto, por exemplo, em um determinado local através de uma atividade, implica particularizá-lo, ou seja, privatizá-lo, não apenas pela especialização dada por seu uso, mas também pelo tipo de vinculação ao grupo de pessoas que passa a se utilizar desse lugar. O que define o "ponto" é o exercício regular de uma determinada atividade. Para os autores, essa atividade pertenceria ao domínio público, pois sem ele não seria possível à criação do mesmo. Entretanto, esse ponto pode ser ou não reconhecido. No caso de não ser, é a própria atividade que confere a sua significação, tornando-o passível de ser identificado.

Os conceitos de apropriação, particularização e privatização quando trabalhados por Santos \& Vogel (1985), contudo, talvez não tivessem a mesma distinção conceitual atual. Hoje, por exemplo, a apropriação pode não implicar necessariamente em uma privatização ${ }^{5}$. É

\footnotetext{
${ }^{5}$ Privatizar aqui é entendido com o sentido de tornar particular, não público. Já apropriar tem o sentido de tornar algo próprio, apoderar-se de algo.
} 
importante ressaltar que a apropriação aqui é entendida como o ato de tomar posse de algo que, a princípio, não lhe pertenceria ou, como é o caso do espaço público, do lugar que pertence a todos.

Nesse sentido, consideramos significativo mencionar a definição de Roger Chartier sobre o conceito de apropriação, que embora relacionado às suas pesquisas no âmbito da História Cultural, nos parece bem interessante por atribuir ao conceito um uso inventivo e criador. Ele nos diz:

Existe a apropriação no sentido da hermenêutica, que consiste no que os indivíduos fazem com o que recebem, e que é uma forma de invenção, de criação e de produção desde o momento em que se apoderam dos textos ou dos objetos recebidos. Desta maneira, o conceito de apropriação pode misturar o controle e a invenção, pode articular a imposição de um sentido e a produção de novos sentidos (CHARTIER, 2001:67).

Para Chartier (2001), no âmbito da cultura, há sempre uma vontade de controle sobre a apropriação, sendo esta o resultado de uma tensão entre o desejo de controle e monopólio (do compositor de uma música ou autor de um livro, por exemplo) e a vontade de conquista (de quem escuta a música ou lê o livro). Isto se dá porque, do lado de quem cria, há a tentativa de fixar um sentido único para a obra, e a apropriação, que é a forma como as pessoas tomam para si o sentido da obra, e que dificilmente pode ser controlada. Para Chartier, portanto, a apropriação se dá nesse conflito.

No nosso caso estamos falando do espaço público, e nele verificamos o conflito latente entre o concebido pelo planejamento urbano e as formas como esse mesmo espaço é vivido e apropriado pelas pessoas. Dessa ambiguidade podem resultar tanto praças abandonadas quanto estacionamentos apropriados por crianças para brincadeiras, por exemplo. Assim, da mesma forma que é possível usar uma caixa de fósforos para fazer música, os indivíduos são capazes de tomar para si, de apropriar-se de espaços, para desenvolver outros usos que não os inicialmente propostos pelo planejador.

Na medida em que a apropriação do espaço aqui analisada se dá por meio do trabalho que é exercido na rua, cabe destacar que este é convertido por essa prática em um novo espaço de consumo e a junção de atividades formais e informais, por sua vez, contribui para a convergência de fluxos que reafirmam a centralidade no lugar onde observamos sua ocorrência. Diversos tipos de apropriação do espaço público são possíveis, porém nos 
chama atenção o fato de que no caso dos trabalhadores de rua, esta apropriação passe a ser reconhecida pelo Poder Público e passe a incorporar o quadro de políticas públicas desenvolvidas pelo Estado. Em outras palavras, isto significa que a apropriação é incorporada pelo planejamento na medida em que ela passa a ser entendida como um direito. Antes, porém, de apresentarmos como as ações do planejamento urbano se deram sobre a atividade do trabalhador de rua nos últimos anos, cabe caracterizar e apresentar a área em estudo: A Avenida Sete de Setembro.

\section{O espaço público em questão: a Avenida Sete de Setembro}

A Avenida Sete de Setembro é uma das principais vias urbanas do município de Salvador. Além de ter sido palco de diversos acontecimentos históricos, ao longo da Avenida Sete estão diversos marcos arquitetônicos importantes como o Mosteiro de São Bento e o Convento das Mercês, por exemplo. Ao analisarmos também a localização da referida Avenida, podemos observar que ela corta alguns bairros do centro antigo de Salvador, os quais não serão detalhadamente apresentados aqui, com exceção ao bairro Dois de Julho, onde também é fortemente notada a presença de trabalhadores de rua.

Em Salvador, as primeiras décadas do século XX podem ter sido marcadas pela estagnação econômica, mas não pela letargia urbana. De acordo com Flexor (2011) os problemas da cidade foram enfrentados sob a luz dos ideais higienistas, bem como foram feitas tentativas de criar condições para a modernização da cidade. Dentre as intervenções do período, destaca-se o alargamento da Avenida Sete de Setembro entre os anos de 1912-1916, principal obra do governo de J.J. Seabra, realizada seguindo os moldes do "urbanismo demolidor" parisiense, que fora protagonizado pelo barão de Haussmann. As obras desse período visavam romper com o traçado colonial, de modo a ordenar e higienizar a cidade que se expandia em direção ao sul. O plano de J.J. Seabra contava com financiamento internacional, que teve seu andamento prejudicado com o acontecimento da Primeira Guerra Mundial. Graças a este fato, diversos prédios históricos deixaram de ser demolidos ao longo do trajeto da avenida, pois os recursos destinados à obra foram reduzidos, o que forçou algumas mudanças na execução do que foi planejado. Ainda assim, conforme Pinheiro (2011) cabe destacar que alguns prédios históricos não escaparam e foram 
demolidos em prol do alargamento da Avenida Sete, como é o caso da Igreja de São Pedro Velho.

Ainda de acordo com Pinheiro (2011) o objetivo da reforma da Avenida Sete era desafogar o Distrito da Sé. 0 traçado da via projetada tem 4,6km de extensão, $21 \mathrm{~m}$ de largura e $3 \mathrm{~m}$ de calçada. Uma parte da avenida está situada no Distrito de São Pedro, área que compreende $1,5 \mathrm{~km}$ do total da via e que outrora fora ocupada pela elite econômica e intelectual de Salvador, porém que passou por um processo de empobrecimento, tendo muitas de suas edificações convertidas em cortiços. A atividade dos trabalhadores de rua é justamente observada no trecho que corresponde ao Distrito de São Pedro, que vai do Mosteiro de São Bento ao Forte de São Pedro. A partir do Campo Grande a Avenida Sete de Setembro faz parte do Distrito da Vitória, uma das áreas mais enobrecidas da cidade, onde partes de seu trajeto são popularmente denominados de Corredor da Vitória e Ladeira da Barra. De lá seu traçado segue até a Barra (figura 1).
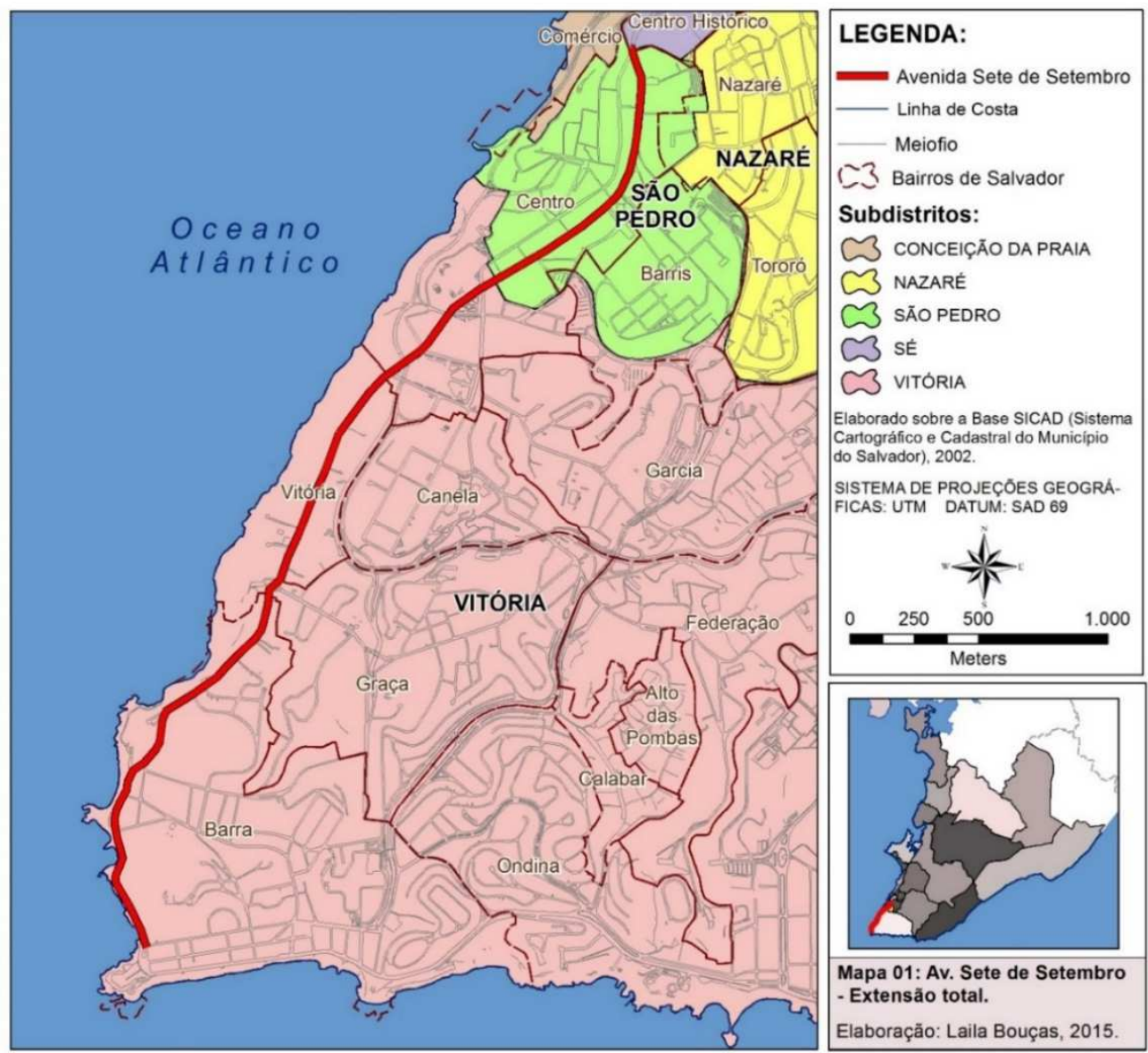

Figura 1 - Av. Sete de Setembro - Extensão total, 2015. Fonte: Elaboração da autora, 2015 
O Centro Antigo e o Centro Histórico de Salvador ${ }^{6}$ aos poucos perderam parte de seu prestígio. Na Rua Chile, por exemplo, que tinha grande importância para o comércio e serviços da cidade, as principais lojas e estabelecimentos de luxo foram deslocados para outras regiões. Segundo Gomes \& Fernandes (1995), já nos anos 1950 o varejo fino da cidade, que antes se concentrava na rua supracitada, começava a se direcionar para a Avenida Sete de Setembro. É de se considerar também o impacto que a ampliação do sistema viário com a abertura das Avenidas de Vale proporcionou à cidade, que pode se desenvolver em novas direções, o que, conseqüentemente, impactou diretamente no fluxo de pessoas que redirecionaram seus deslocamentos para novas centralidades.

Na década de 1960, segundo Margarete Oliveira (2003), a criação do Centro Industrial de Aratu ( $\mathrm{ClA})$, dentre outros fatores, contribuiu para que o crescimento físico da cidade fosse direcionado para o vetor norte. Nessa região, além do favorecimento da malha viária, a construção do Shopping Iguatemi Salvador, a implantação da Estação Rodoviária e o Centro Administrativo da Bahia (CAB) na Avenida Paralela foram empreendimentos que redirecionaram e redimensionaram os fluxos da cidade.

Esse conjunto de acontecimentos contribuiu para que o Centro Antigo e sua principal avenida vissem a sofisticação e o luxo outrora existentes serem substituídos por um varejo mais popular. Contudo, o fluxo de pessoas que se deslocam diariamente para a área não se tornou menos importante. Nesse contexto, assume grande destaque um equipamento erguido nas proximidades da Avenida Sete: a Estação da Lapa, inaugurada na década de 1980. Para o terminal de transporte da Estação da Lapa se dirigem, segundo a Transalvador (2010), 92 linhas de transporte, num contingente de cerca de 278 ônibus/hora ou cerca de 260.000 passageiros/dia. Ressalta-se ainda que, no ano de 2014 , houve a inauguração da Linha 1 do metrô, que atualmente vai da Estação da Lapa até o Acesso Norte, e que transportou no mês de abril de 2015 uma média de 31 mil usuários por dia, segundo informações contidas no site da Secretaria de Desenvolvimento Urbano (Sedur ${ }^{7}$ ). Cabe ainda destacar que na região há também duas grandes superfícies comerciais: os shoppings centers Lapa e Piedade, que atraem um número significativo de viagens, o que pode ser constatado pelos números apresentados por suas administrações, que informam em seus

\footnotetext{
${ }^{6}$ O Escritório de Referência do Centro Antigo da Cidade de Salvador em convênio com a Organização das Nações Unidas para a Educação, a Ciência e a Cultura (UNESCO) apresenta uma delimitação onde são considerados o Centro Histórico e o Cento Antigo da cidade. Nesta delimitação o Centro Histórico compreende a área que vai da Rua Chile ao Santo Antônio. Já o Centro Antigo abrange o Centro Histórico, Campo Grande, Politeama, Centro, Barris, Tororó, Jardim Baiano, Nazaré, Barbalho, Lapinha, Comércio, Água de Meninos, Sieiro, Queimadinho, Liberdade e Calçada.

${ }^{7}$ http://www.sedur.ba.gov.br/
} 
sites que por ali circulam cerca de 70 e 100 mil pessoas/dia, respectivamente ${ }^{8}$. Essas estimativas sobre o número de pessoas que circulam na área indicam não somente 0 volume de transeuntes, mas também o grande número de empregos que a região concentra, sejam eles formais ou informais.

A Avenida Sete de Setembro, então, mantém sua grande importância para a cidade, pois corta uma área onde há grande concentração de atividades comerciais e de serviços, além de instituições como igrejas e escolas. Ainda é palco dos principais eventos cívicos e de protesto que acontecem na cidade e, por contar com um grande número de transeuntes que se deslocam diariamente pelo local, seja para trabalhar, estudar ou consumir mercadorias e/ou serviços, tende a ser bastante procurada por trabalhadores de rua para desenvolver suas atividades laborais. Por este motivo, diversas intervenções foram e são planejadas pelo poder público. Intervenções e propostas que datam desde o século XIX, no período próximo à abolição da escravatura, quando escravos de ganho e quitandeiras podiam comercializar produtos apenas em cantos específicos da cidade. Não será possível, entretanto, aprofundarmo-nos nessas questões históricas, pois o recorte aqui proposto é contemporâneo. Contudo, não poderíamos deixar de pontuar que este é também um traço histórico, que demonstra como o ato de utilizar o espaço da rua para vender mercadorias faz parte da nossa herança cultural. Apresentaremos a seguir as principais ações de planejamento que incidiram sobre a referida Avenida, entre os anos de 1992 e 2014.

\section{Projetos elaborados para regulação da atividade do trabalhador de rua em Salvador/BA}

O exercício da atividade comercial em via pública vem sendo alvo de intervenções do poder público, que tem suas ações tanto no sentido de coibir quanto de regular a atividade. No recorte de tempo aqui proposto, entre 1988 e 2014 ${ }^{9}$, na cidade de Salvador, foram elaboradas algumas propostas por distintas gestões municipais no sentido de organizar a atividade do trabalhador de rua na região da Avenida Sete e do bairro Dois de Julho, mais precisamente nos anos de 1992, 1997 e 2014. Cada um dos projetos será brevemente

\footnotetext{
${ }^{8}$ www.shoppinglapa.com.br; www.shoppingpiedade.com.br

${ }^{9}$ Esse recorte temporal foi escolhido para melhor compatibilizar a contextualização entre os projetos encontrados e os fenômenos observados na sociedade e na economia em função da redemocratização do país, promulgada com a Constituição Federal de 1988.
} 
apresentado, focando principalmente nas principais características de cada um dos tipos de intervenção.

O primeiro projeto foi proposto no ano de 1992, na gestão do prefeito Fernando José Guimarães Rocha e contou com consultoria de dois economistas de referência: João Carlos Araújo e Fernando Pedrão. No relatório do projeto, há uma importante contextualização e diagnóstico da informalidade à época, destacada como um dos mais relevantes problemas da cidade. A referida proposta tinha a pretensão de "implementar uma solução urbanística que integre os trabalhadores atualmente localizados em um dos mais importantes e tradicionais espaços da cidade" (PREFEITURA MUNICIPAL SALVADOR, 1992:4). Este espaço é sinalizado como o circuito compreendido entre a Praça da Sé e o Campo Grande.

Para aquela gestão da prefeitura, a utilização do espaço público implicava em custos e as atividades localizadas nos logradouros públicos deveriam, portanto, dentro de suas possibilidades, contribuir com a manutenção desses locais. Além das propostas de intervenção urbanística que visavam tanto organizar a atividade no local, quanto redistribuila na cidade, havia também diretrizes no âmbito social no sentido de incentivar a promoção de programas para orientação e qualificação do trabalhador de rua.

Fica evidenciado, através do relatório, que a intenção da prefeitura naquele período era de implementar uma política voltada para as atividades informais, nas quais estavam incluídas a atividade do trabalhador de rua (ambulantes), das barracas de praia, bancas de chapa e feirantes. Nota-se ainda uma preocupação de incorporar a problemática da informalidade no planejamento urbano da cidade, pois a proposta conta com o estabelecimento de diretrizes para a questão e não somente com uma orientação para intervenções pontuais.

O relatório do referido projeto nos traz um pouco da evolução pela qual o conceito da informalidade passou desde a década de 1970, destacando a imprecisão conceitual utilizada e a pluralidade de formas de trabalho nas quais se inclui o uso do termo. Contudo, considera-se que tais conceitos têm pouco a oferecer se não forem postos em contato com a realidade do cotidiano urbano. Neste sentido, a informalidade é compreendida no âmbito do projeto como um produto da urbanização, fruto da atividade urbana contínua, onde cada tipo de cidade possui um quadro de informalidade correspondente, cuja composição muda ao longo do tempo, o que reflete as mudanças demográficas e econômicas pelas quais a cidade passa. Reconhece-se então que a informalidade transcende a questão da marginalidade e reflete estratégias de sobrevivência de trabalhadores excluídos do mercado formal, de maneira que não parece muito interessante a proposição de políticas que ignorem a questão ou visem extingui-la. 
Tendo em vista esta concepção da informalidade pelo poder público à época, o objeto das intervenções se concentraram em dois eixos: o primeiro, no que se refere às atividades informais exercidas em logradouro público e o segundo, na implementação de uma política social voltada para redefinir o quadro de pobreza urbana verificado na cidade. Para orientar os estudos e proposições foram também pensados alguns possíveis cenários futuros no que se refere ao desempenho da economia baiana, onde se revelou como mais provável o cenário que previa uma estagnação generalizada da economia, com a continuidade de uma política recessiva do governo federal, ausência de investimentos e aumento do subemprego e emprego. Tal perspectiva apontava para a necessidade de que o município de Salvador viesse a assumir iniciativas voltadas para sustentar o nível de ocupação e renda de sua população, atuando não apenas de forma ordenadora.

Os resultados das pesquisas realizadas indicaram, dentre outros fatores, que havia uma expressiva demanda de consumo que só podia ser atendida por este tipo de comércio, que ofertava mercadorias a preços menores. Além disso, o mercado informal se apresentava também como alternativa de sobrevivência de parcela importante da população. Estes fatores são apontados pelo referido estudo como motivação para adoção de uma postura proativa da prefeitura com relação a atividade, a quem caberia a criação de condições favoráveis para que essas pessoas pudessem garantir o seu sustento. Neste sentido, há uma importante indicação no que diz respeito a integração da questão da informalidade ao planejamento urbano da cidade, de modo a tratá-la não apenas como uma problemática isolada ou setorial.

$\mathrm{Na}$ gestão do prefeito Antônio Imbassahy foi elaborado um novo projeto com vista ao ordenamento do comércio informal na cidade de Salvador, publicado no ano de 1997. O projeto faz referência aos estudos realizados em 1992, reconhecendo o cenário de agravamento da crise na economia nos anos 1990 apontado por aquele estudo, que colaborou efetivamente com a crise no emprego e levou muitos trabalhadores a recorrerem ao mercado informal como uma alternativa de sobrevivência.

De acordo com as análises realizadas em 1997, a dinâmica do centro antigo foi mantida e tensionada principalmente em razão do movimento de passageiros da Estação da Lapa e da presença dos diversos serviços disponíveis neste lugar, o que o constituiu como a maior concentração de trabalhadores de rua da cidade. Considerando que o projeto proposto em 1992 não foi efetuado, o projeto de 1997 toma os objetivos do trabalho anteriormente citado como referência, porém com a pretensão de efetuar uma intervenção de caráter emergencial. Acreditamos que tal caráter emergencial, embora não esteja explicitado nos relatórios encontrados, se relaciona com a crise do emprego dos anos 1990 que influenciou 
diretamente no aumento da informalidade. Entre os objetivos desta gestão estão: gerir os conflitos existentes entre a atividade do comércio informal e os interesses globais da população; assegurar o uso coletivo dos espaços públicos; compatibilizar a atividade com o sistema de circulação de pedestres; evitar o comprometimento da paisagem e do patrimônio em decorrência da atividade do comércio informal; e padronizar os equipamentos utilizados pelos trabalhadores.

O estudo verificou a existência de 1.620 pontos de comercialização existentes na Av. Joana Angélica e Av. Sete de Setembro. De acordo com as informações contidas no relatório, houve um crescimento de $64,47 \%$ da atividade nesta área desde 1992 , onde se destaca a comercialização de aparelhos eletro-eletrônicos. A comercialização de tais artigos importados, por sua vez, é considerada como incompatível com as características do centro antigo, e contribuiriam para descaracterizar o desenho desta região da cidade, pois demandariam uma ampliação dos passeios em função do espaço para exposição que demandam, o que, consequentemente, viria a prejudicar o desempenho e a fluidez do trânsito. Tais motivos justificavam o remanejamento da atividade para outros locais.

A proposta da gestão do prefeito Imbassahy era de ordenar a atividade confinando-a em trechos específicos e transversais existentes do lado esquerdo da Avenida Sete de Setembro, no sentido de quem está na Praça Castro Alves e vai para o Campo Grande, com exceção ao trecho correspondente à Ladeira de São Bento, onde se permitiria a ocupação em ambos os lados. Nestes trechos haveria a instalação de baias e corrimãos de proteção. Para a execução da proposta, previa-se a transferência dos trabalhadores da Praça da Piedade e Praça Rio Branco (Relógio de São Pedro) para as transversais. Do Largo de São Bento deveriam ser retirados todos os trabalhadores do comércio informal, restando apenas um ponto para comercialização de acarajé.

Enquanto os estudos de 1992 reconheciam que os produtos comercializados na região eram em sua maioria de gêneros alimentícios e que isso demandaria uma ação de orientação do poder público no que se refere à higiene, o estudo de 1997 informa não ter realizado um zoneamento por tipo de mercadoria, mas que "as precárias condições de higiene na comercialização de frutas e verduras, determinaram a sua exclusão das atividades permitidas" (PREFEITURA MUNICIPAL DE SALVADOR, 1997, p.9).

Apesar de ser inspirado na proposta elaborada em 1992 (Figura 2), o projeto de 1997 (Figura $3)$, segrega a atividade do comércio informal, pois prevê a sua retirada quase completa da Avenida Sete e da Avenida Joana Angélica. Por tratar-se de uma medida de caráter emergencial, a atualização da pesquisa feita pela proposta da gestão anterior também não é totalmente realizada, limitando-se apenas à elaboração de um novo quantitativo por área e 
das estimativas de crescimento ou decréscimo da atividade entre os períodos analisados. Além disso, fica evidente o caráter repressivo da medida, uma vez que não são propostas soluções para casos como o da comercialização de frutas e verduras, por exemplo, colocando a atuação da prefeitura no sentido da proibição da venda desses produtos.

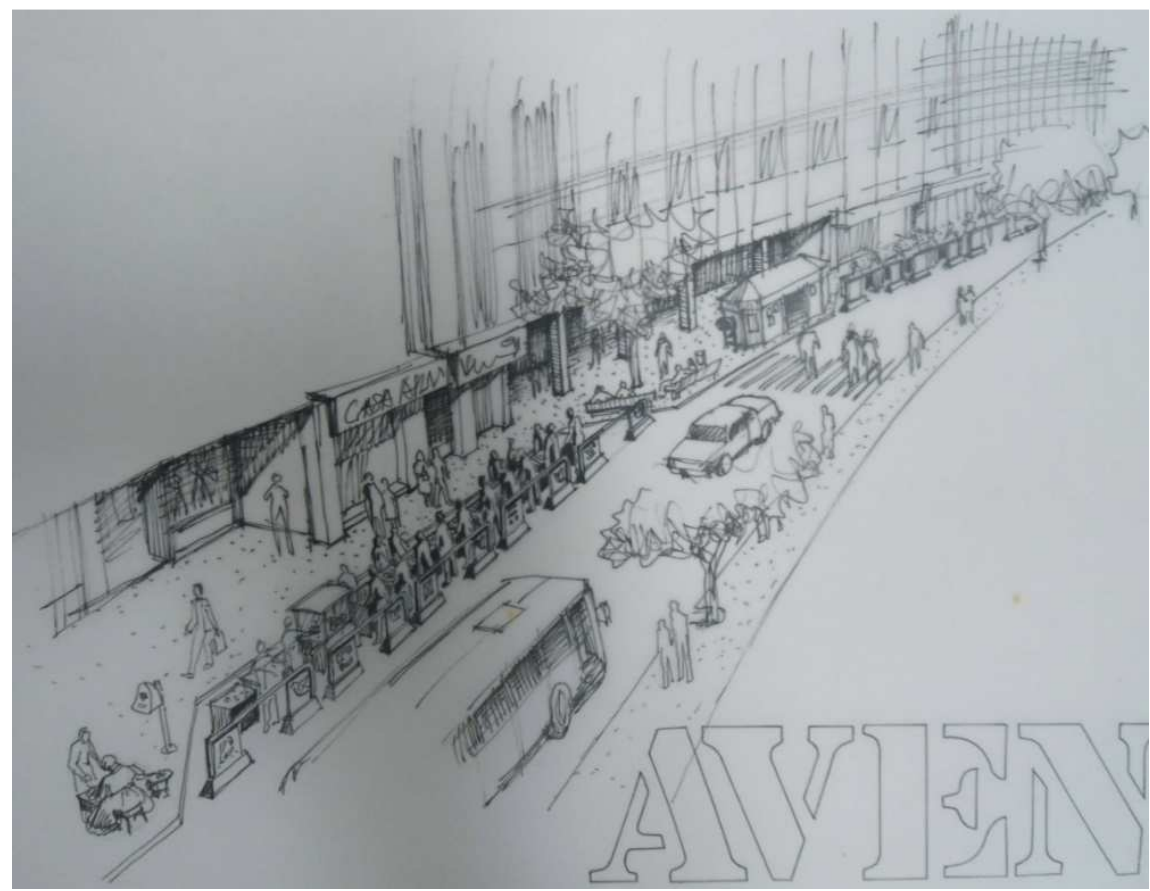

Figura 2 - Croquis do projeto para Av. Sete - Salvador, 1992. Fonte: Salvador, 1992

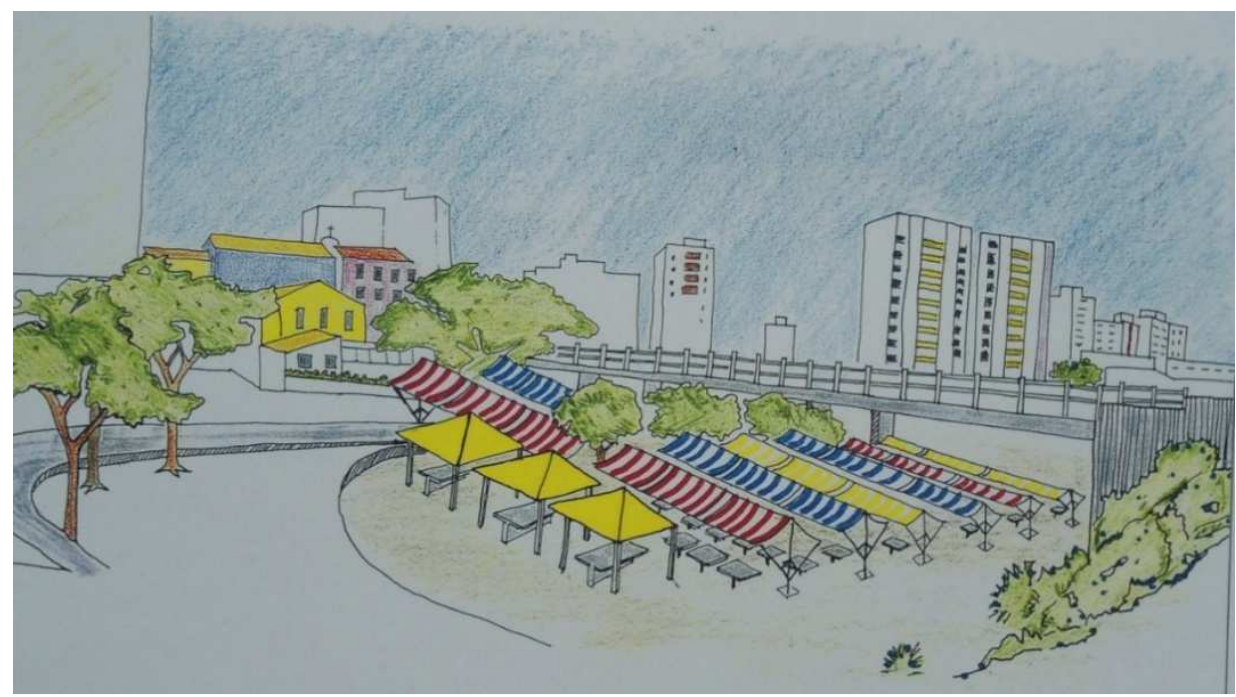

Figura 3 - Avenida Sete de Setembro. Área 3 - perspectiva da área (Rua do Cabeça/Estacionamento São Raimundo). Fonte: Salvador, 1997

Somente em 2014 a questão do trabalhador de rua voltou a ser tratada no âmbito do planejamento urbano da cidade de Salvador, após um hiato de 10 anos sem que nenhuma 
proposta fosse apresentada pelo poder público, período que corresponde à gestão do prefeito João Henrique Carneiro, eleito duas vezes entre os anos de 2005 à 2012. Esta lacuna no tratamento da questão justificou uma ação, também realizada em caráter emergencial, pela gestão do prefeito Antônio Carlos Magalhães Neto, iniciada no ano de 2013, poucos meses após sua posse. Ressaltamos que o caráter emergencial desta vez não se relaciona com uma crise no emprego, já que no referido período houve decréscimo da taxa de desemprego no país. A emergência parece estar relacionada, então, com a ausência da questão nas políticas públicas propostas e realizadas pelo poder público na gestão anterior. Cabe destacar também que a nova gestão da prefeitura tem tido ações que privilegiam os interesses corporativos e gentrificadores na região do centro antigo da cidade, sobre os quais não poderemos nos aprofundar no momento. ${ }^{10}$

A ação proposta no âmbito da gestão 2013-2016 vem sendo executada através da Secretaria de Ordem Pública (SEMOP), que carrega em si a missão disciplinadora do espaço público. Sua intervenção aparece no âmbito do plano de requalificação e reordenamento de ambulantes de Salvador, que se desdobra em três projetos principais: Requalificação da Av. Sete de Setembro - ordenamento do comércio informal; Requalificação do Mercado 2 de Julho; e Projeto Avenida Sete - território empreendedor.

Aqui nos detemos as informações contidas no projeto: "Requalificação da Av. Sete de Setembro - ordenamento do comércio informal", porém, não foi possível ter acesso ao plano de maneira integral, pois o mesmo não foi publicado, nem tampouco disponibilizado pela atual gestão. Contudo, teve-se acesso aos documentos das ações mencionadas anteriormente, onde constam basicamente pranchas de plantas baixas e vistas do projeto executado. ${ }^{11}$ Diferentemente do que se relata sobre o projeto elaborado em 1997 na gestão de Imbassahy, o processo de ordenamento de 2013-2015 contou com a realização de reuniões entre as associações e sindicatos de trabalhadores do comércio informal e o poder público, com parceria do SEBRAE. Após a realização dessas reuniões com as lideranças, a nova secretaria chega a um projeto que prevê a transferência de todos os trabalhadores da Avenida Sete de Setembro para as transversais constantes na figura 4, contemplando apenas aqueles que possuem licença.

\footnotetext{
${ }^{10}$ Cabe mencionar uma declaração proferida pela secretaria de Ordem Pública, que põe em evidencia uma tentativa de uniformização do espaço apoiada no discurso da necessidade de ordenamento do centro da cidade. Ela declarou de forma polêmica no início da nova gestão que "enfrentamos dificuldades na estética da cidade. Precisamos realizar um trabalho de maquiagem para receber [os visitantes]... Mas não só para isso, mas também tornar a cidade boa para quem mora aqui. Esse que é o objetivo principal” (Mendes, 2012).

${ }^{11}$ Para auxiliar no entendimento do processo e na ausência de documentos oficiais fornecidos pela prefeitura, foram utilizadas também informações contidas nas publicações do Diário Oficial do Município e em jornais de grande circulação no município.
} 


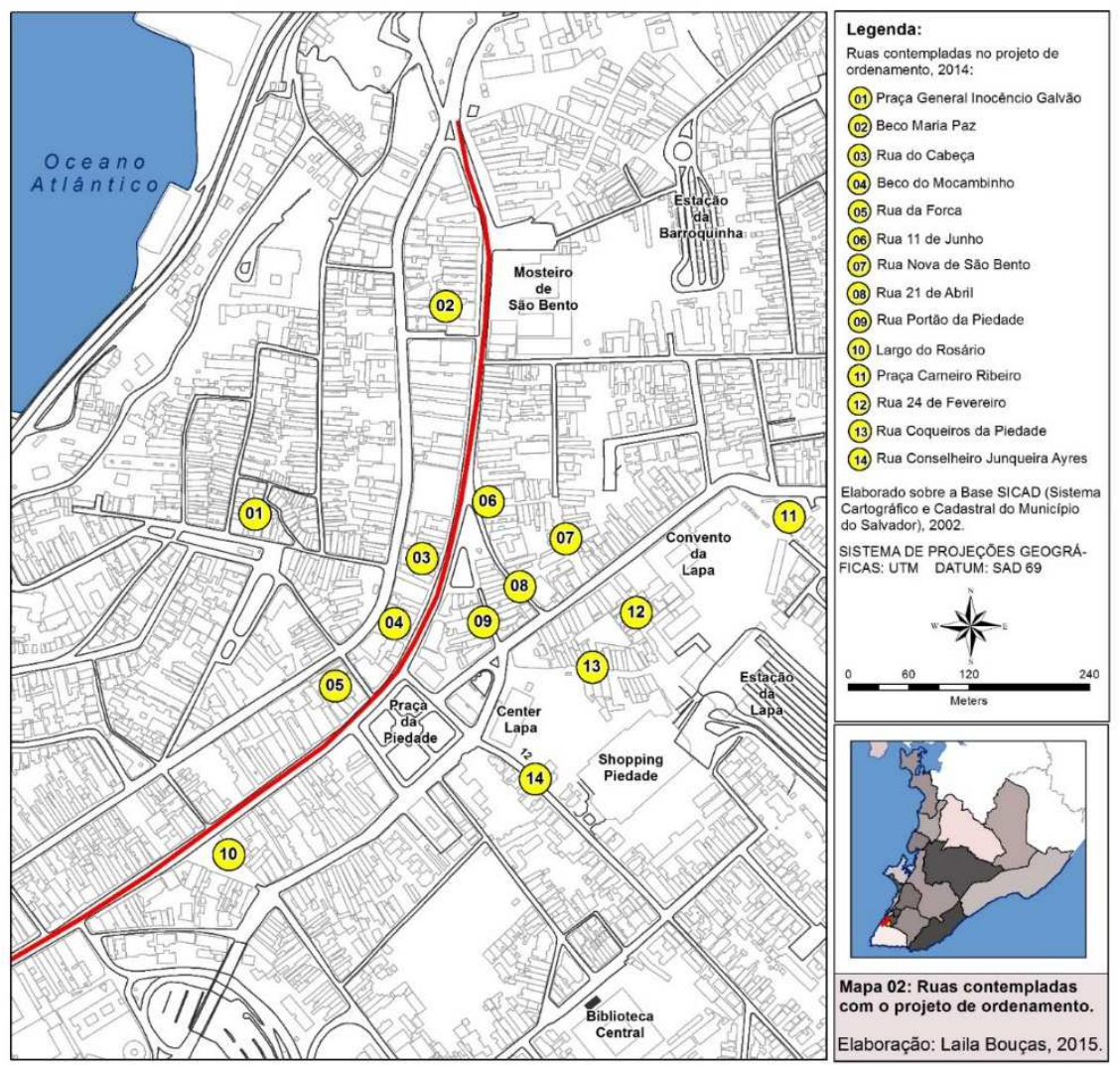

Figura 4 - Ruas contempladas com o projeto de ordenamento de 2014. Fonte: Elaboração da autora, 2015.

Iniciado no mês de junho do ano de 2013, no final do ano de 2014 a obra já contava com a reforma estrutural de praticamente todas as transversais da Avenida Sete de Setembro, restando apenas para conclusão a reforma da Praça do Relógio de São Pedro, Rua Onze de Junho, Rua Vinte e Um de Abril e Rua Nova de São Bento. Na Figura 5 pode-se observar o que fora divulgado por meio de jornais de circulação local a respeito do projeto de requalificação. Trata-se de perspectivas da nova estrutura de trabalho e mobiliário proposto. A Figura 6 traz o registro de uma das ruas que já passaram pela reforma. 


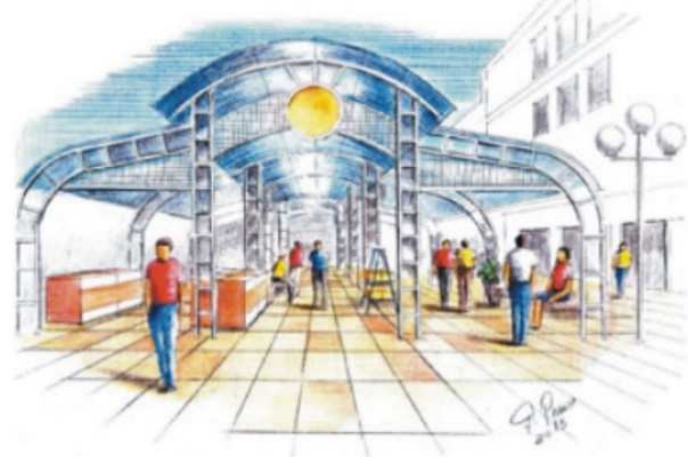

Figura 5 - Largo do Rosário após a reforma. Fonte: Correio da Bahia, 2013.

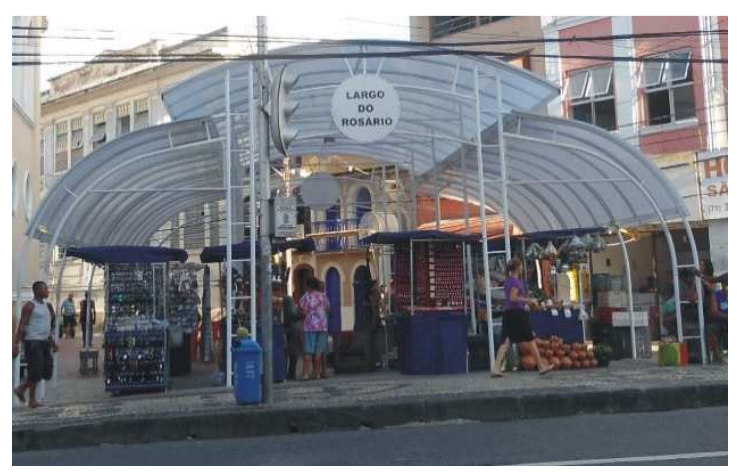

Figura 6 - Largo do Rosário em croqui apresentado pela prefeitura. Fonte: Foto da autora, 2014

Nas 13 áreas o projeto executado conta com obras de saneamento, iluminação e pavimentação, onde a pedra portuguesa foi substituída por piso intertravado e se inseriu rota acessível para o uso de pessoa com deficiência visual. Houve também a implantação de cobertura em policarbonato sobre estrutura metálica (SALVADOR, 2014). Alguns aspectos relativos à implantação do projeto, entretanto, são questionáveis. É o caso, por exemplo, da não existência de calhas para captar e canalizar a água da chuva e do conforto térmico.

\section{Considerações finais}

O mercado de trabalho brasileiro é marcado pelos efeitos de uma industrialização tardia, que destruiu as ocupações tradicionais de boa parte da população. Se no campo a estagnação ou a mecanização diminuíram as possibilidades de trabalho das pessoas por substituí-las, nas cidades, passou-se a aglutinar uma grande massa populacional que não foi absorvida pelo mercado de trabalho que começava a se consolidar. Um mercado que, portanto, sempre foi excludente, e que traz as cicatrizes de um passado baseado num regime escravista, sobretudo considerando a cidade de Salvador. Às margens desse mercado e com poucas perspectivas de inserção provocadas por desigualdades históricas, como o acesso precário à educação, saneamento básico, saúde, habitação, etc., temos indivíduos que buscam a sobrevivência através de formas criativas, porém também frequentemente bastante precarizadas. Assim, vimos brevemente como esses traços foram aprofundados, sobretudo na década de 1990, quando a globalização e a reestruturação produtiva pela qual o mundo capitalista passou contribuíram para um agravamento da situação. 
Tais acontecimentos têm diversos desdobramentos no espaço, como a ocupação de áreas inadequadas para a moradia e comumente distantes dos centros urbanos, por exemplo. $\mathrm{Na}$ perspectiva em que trabalhamos, esse desdobramento se dá numa escala de maior proximidade, na escala da rua e do cotidiano. Aos olhos de todos, ricos ou pobres. No olho da rua de um dos centros comerciais de maior importância para a cidade de Salvador. Situação, contudo, que não é exclusiva de nossa cidade: repete-se em muitas outras capitais brasileiras, de formas ao mesmo tempo particulares e semelhantes.

A atividade do trabalhador de rua, nesse contexto, assume real importância tanto por questões sociais, uma vez que garante uma forma de sustento para aqueles que nela se ocupam, quanto pelo capital que movimentam, visto que contribuem para o escoamento de mercadorias que também são produzidas pelo circuito superior. A apropriação do espaço pela atividade se incorpora ao cotidiano e estabelece novas relações entre aqueles que usam este espaço.

Em Salvador, a dinâmica criada pela atividade e as diversas instâncias que este trabalho movimenta, criam contradições ao mesmo tempo em que lhe enchem de vida. A atividade pode ser lida também como um resultado da diversidade de usos existentes na área. É como se os trabalhadores sentissem a concentração e potência dessa diversidade para a exposição de seus produtos e a aproveitassem, dinamizando e ampliando ainda mais as possibilidades do lugar. O trabalho na rua aparece assim como uma alternativa de sobrevivência ao indivíduo socialmente vulnerável, através da qual lhe é possível viver com alguma dignidade, e sua presença nas ruas é capaz de proporcionar uma intensificação da experiência de estar, viver e pertencer à cidade.

É importante ter em vista, nesse sentido, que a apropriação não deixa de ser tensionada mesmo quando convertida em um uso legitimado. Isto ocorre porque o lugar onde a apropriação que estamos lidando ocorre, a rua, é um lugar em permanente disputa. A calçada que já é uma porção reduzida da rua, agrega pelo menos a área destinada ao mobiliário urbano, o passeio do pedestre e a área acesso aos estabelecimentos e residências. Isso sem contar os demais usos e apropriações que se faz dela como, por exemplo, quando uma pessoa em situação de rua delimita uma porção deste espaço para dormir. Nesse sentido, a permanência nesse espaço limitado pressupõe um conflito constante entre diversos direitos, como o direito de ir vir, o direito à cidade e o direito ao trabalho, por exemplo. 
Podemos considerar que a rua enquanto lugar de disputa, é ainda mais tensionada quando o poder público lhe impõe normas e regras de uso. No caso da atividade dos trabalhadores de rua, a qual estudamos, pudemos perceber essa tensão constante sobretudo porque as pessoas não querem trabalhar em ruas onde não há movimento, ou seja, em ruas onde não há possibilidade de vender. A sua necessidade de sobrevivência se sobrepõe à ordem estabelecida. Desta forma, os locais onde a atividade não deveria mais acontecer sofrem pressões permanentes, assim como re-apropriações constantes, ocorridas durante e após cada intervenção tentada pelo poder público.

Dentre as tentativas de ordenamento que estudamos, pudemos notar que entre 1992 e 2014 houve basicamente três propostas no que se refere a atividade do trabalhador de rua em Salvador. A primeira delas foi realizada com base em estudos mais aprofundados sobre a temática, sintetizados em uma proposta que integrava a atividade com os demais usos do espaço público, porém sem se concretizar. Tal proposta sobressai por assimilar o trabalho de rua como fenômeno inerente à economia soteropolitana e passível de integrar a política pública urbana. A segunda proposta, apesar de partir da análise anterior, praticamente repeliu toda a atividade da rua onde se manifestava com mais intensidade, redirecionandoa apenas para alguns pontos específicos, o que foi desfeito na medida em que a fiscalização constante desses locais não foi praticada, sobretudo no intervalo entre a transição de uma gestão para outra. Neste caso, a normatização do uso não impediu que a apropriação voltasse a se manifestar em outros momentos. A última e mais recente proposta, apesar de também intencionar a retirada de todos os trabalhadores da rua principal, da Avenida Sete de Setembro, cria algumas condições para a sua permanência em locais determinados ao implantar algumas estruturas de suporte, o que não garante a efetividade da proposta.

O lugar que a atividade ocupa é de interesse de todos, uma vez que se trata do espaço público. Este, por sua vez, não é escolhido aleatoriamente por cada um daqueles que dele se apropria. Para o desenvolvimento da atividade aqui estudada vemos que as características funcionais deste espaço perpassam por sua localização na cidade, nas quais diversos fluxos são articulados. Assim, ações do poder público podem ser concebidas, com o intuito de organizar, ordenar ou coibir os usos considerados não compatíveis com os interesses que se tem para o lugar. Vale ressaltar também que as recentes intervenções executadas promovem uma segregação da atividade do trabalhador de rua para transversais específicas, liberando a Avenida Sete, vetor principal de circulação entre importantes pontos turísticos como o Centro Histórico com a Barra, da presença e imagem desse trabalhador. 
Ainda que as permissões para que os trabalhadores de rua possam explorar o logradouro público sejam precárias, ou seja, possam ser retiradas no momento em que este seja o interesse da prefeitura, isto não significa necessariamente que a atividade possa ser eliminada. Através dos projetos elaborados desde 1992 para cá ficou evidenciada a compreensão da funcionalidade desse setor da economia, cuja vivacidade se relaciona com a força social dos trabalhadores de rua que movimentam e contribuem para o escoamento das mercadorias no circuito inferior da economia, bem como a resistência desses próprios trabalhadores em permanecer ou retornar para os locais dos quais buscam se apropriar. Trata-se, portanto, de uma situação que não pode ser ignorada pelo poder público e que o planejamento possivelmente só será capaz de enfrentar a partir do momento em que busque compreender sua complexidade e proponha alternativas que compatibilizem os diferentes interesses envolvidos, sem a intenção de eliminar as práticas cotidianas dos espaços de representação, ou seja, do âmbito do vivido, utilizando aqui os termos de Lefebvre, pois estas tendem a voltar ou resistir, tensionando o espaço público, seus usos e apropriações.

\section{Referências bibliográficas}

ARANTES, Otília; VAINER, Carlos; MARICATO, Ermínia. A cidade do pensamento único. 7. ed. - Petrópolis, RJ: Vozes, 2012.

ARAÚJO, Solange Souza. Tipomorfologia das praças e largos de Salvador: intervenções em espaços do centro antigo (1980-2005). 2006. 333 f. Tese (Doutorado) - Faculdade de Arquitetura e Urbanismo, Universidade Federal da Bahia, Salvador, 2006.

BORGES, Ângela. Mercado de trabalho: mais de uma década de precarização. In: DRUCK, G.; FRANCO, T. (Org.). A perda da razão social do trabalho: terceirização e precarização. São Pauto: Boitempo, 2007.

BORJA, Jordi. La ciudad conquistada. Madrid: Alianza Editorial, S.A., 2003.

BORJA, Jordi; MUXÍ, Zaida. El espacio público, ciudad y ciudadanía. Barcelona: Electa, 2000.

BOUÇAS, Rose Laila de Jesus. No olho da rua: trabalho e vida na apropriação do espaço público em Salvador/BA. Dissertação (Mestrado) - Programa de Pós Graduação em Arquitetura e Urbanismo da Universidade Federal da Bahia. Salvador, 2015.

CHARTIER, Roger. Cultura escrita, literatura e história. Conversas de Roger Chartier com Carlos Aguirre Anaya Rosique, Daniel Goldin e Antonio Saborit. Porto Alegre: Artimed, 2001.

COSTA, Márcia da Silva. Trabalho Informal: um problema estrutural básico no entendimento das desigualdades na sociedade brasileira. In: Caderno CRH: Revista do Centro de Recursos Humanos da UFBA. v. 23, n.58. p 171190, Jan./Abr. 2010. Salvador: UFBA, 2010.

DIEESE. As mudanças de composição, intensidade e duração do desemprego urbano entre 1999 e 2009: um olhar sobre o desemprego de longo prazo / Departamento Intersindical de Estatística e Estudo Socioeconômicos. São Paulo: DIEESE, 2011. 
FLEXOR, Maria Helena. Salvador e o Higienismo nos séculos XIX e XX. In: A Urbanização de Salvador em três tempos - Colônia, Império e República. Textos críticos de História Urbana / Jaime Nascimento; Hugo Gama. (orgs.) Vol 1. Salvador: Instituto Geográfico e Histórico da Bahia, 2011.

FILGUEIRAS, Luiz, A, M.; DRUCK, Graça; AMARAL, Manoela Falcão do. O Conceito de informalidade: um exercício de aplicação empírica. In: Caderno CRH: Revista do Centro de Recursos Humanos da UFBA. v.17, n.41. p. 211-229, Mai./Ago. 2004. Salvador: UFBA, 2004.

GOMES, M. A. A. F.; FERNANDES, Ana. Pelourinho: Turismo, Identidade e Consumo Cultural. In: Marco Aurélio A. de F. Gomes. In: Pelo Pelô: história, cultura e cidade. Salvador: EDUFBA, 1995.Org.

JACOBS, Jane. Morte e vida de grandes cidades. Tradução Carlos S. Mendes Rosa; revisão da tradução Maria Estela Heider Cavalheiro; revisão técnica Cheila Aparecida Gomes Bailão. - 3a ed. - São Paulo: Editora WMF Martins Fontes, 2011.

LEFEBVRE, Henri. La production de l'espace. 4a ed. Paris: Anthropos, 2000.

MOLLIER, Jean-Yves. O camelô: figura emblemática da Comunicação / tradução: Fatima Murad - São Paulo: Editora da Universidade de São Paulo, 2009.

OLIVEIRA, Francisco de. Crítica a razão dualista: O ornitorrinco. São Paulo: Boitempo, 2003.

OLIVEIRA, Margarete Rodrigues Neves. A Área do Iguatemi: O novo centro econômico da cidade do Salvador. Uma Análise da produção espacial de novas centralidades. 125p. Dissertação (Mestrado) - Pós Graduação em Geografia. Instituto de Geociências da Universidade Federal da Bahia, 2003. Disponível em: <http://www.posgeo.ufba.br/disserta\%C3\%A7oes/Margarete_disserta_o_mestrado.pdf> Acesso em: 22 jun. 2009.

PINHEIRO, Eloísa Petti. Europa, França e Bahia: difusão e adaptação de modelos urbanos (Paris, Rio e Salvador). 2 ed. - Salvador : EDUFBA, 2011.

PREFEITURA MUNICIPAL DE SALVADOR. Centro do Planejamento Municipal. O informal em Salvador: política e propostas. vol. 1 e 2. Salvador: 1992.

PREFEITURA MUNICIPAL DE SALVADOR. Centro do Planejamento Municipal. Comércio informal: relocação dos ambulantes da Av. Sete de Setembro; memória dos trabalhos realizados. Salvador: 1997.

PREFEITURA MUNICIPAL DE SALVADOR. TRANSALVADOR - Superintendência de Trânsito e Transporte do Salvador. Anuário de transportes urbanos de Salvador Ano XXII, 2010. Salvador: 2010.

SAMPAIO, Antônio Heliodório Lima. Formas urbanas: cidade-real \& cidade-ideal ; contribuição ao estudo urbanístico de Salvador. Salvador. BA.: Universidade Federal da Bahia, Faculdade de Arquitetura: Quarteto, 1999.

SANTOS, Milton. Espaço e método. São Paulo: Nobel, 1985.

SANTOS, Milton. O espaço dividido: os dois circuitos da economia urbana dos países subdesenvolvidos / Milton Santos; tradução Myrna T. Rego Viana - 2. ed. 1. reimpr. - São Paulo: Editora da Universidade de São Paulo, 2008.

SANTOS, Carlos Nelson F.; VOGEL, Arno. Quando a rua vira casa. 3. ed. São Paulo: Projeto, 1985. 